\title{
MEALS, ART AND MEANING
}

\author{
EILEEN JOHN \\ University of Warwick \\ Department of Philosophy \\ eileen.john@warwick.ac.uk
}

SUMMARY: This paper takes meals, rather than food itself, as its focus. Meals incorporate the project of nutrition into human life, but it is a contingent matter that we nourish ourselves in this way. This paper defends the importance of meals as meaning-makers and contrasts them with art in that regard. Meals and art represent interestingly different extremes with respect to how needs for meaning are met. Artworks ask for coordination of experience, understanding and appreciation: the meaning of art is to be experienced. The meaning of meals is enacted and accumulates collectively, but need not be experienced.

KEY WORDS: food and art, food, Yuriko Saito, Richard Wollheim, Joseph Margolis

RESUMEN: Este artículo se enfoca en comidas —ocasiones/eventos donde se comeLas comidas incorporan el proyecto de la nutrición en la vida humana, pero la manera en la que nos nutrimos es algo contingente. Este artículo defiende la importancia de las comidas como actos creadores de significado, contrastándolas con el arte. Las comidas y el arte representan, de forma interesante, diferentes extremos de la necesidad de crear significado. Las obras de arte requieren experiencia, comprensión y apreciación: el significado del arte debe venir de la experiencia del mismo. El significado de la comida se ejecuta y se acumula colectivamente, y no necesita experimentarse.

PALABRAS CLAVE: comida y arte, comida, Yuriko Saito, Richard Wollheim, Joseph Margolis

\section{Introduction}

Some time ago I read an article entitled "The End of Food", about a product that, with oil and water added, provides complete daily nutrition for a human being (Widdicombe 2014). My initial reaction was that the title should have been "The End of Meals". I thought that this product was clearly food - a nourishing substance that people ingest for that reason - but that it represented more importantly a dismissal of the practice of having meals. ${ }^{l}$ The developer took its

${ }^{1}$ The focus of the article, Soylent, seems to claim meal status for its pre-mixed product, as 'a ready-to-drink meal'. Classification as food also seems to be claimed: it is 'food reformatted' (<https://soylent-uk.com/ $>$ ). 
convenience, as a nourishing substance that could be sipped at any time, to be a key virtue. Now it seems less obvious to me that products such as this should be classified as food. Maybe a foodstuff has to have some identity beyond its nutritional potential, some qualities that support but do not collapse into being nutrients. ${ }^{2}$ Perhaps our conception of food needs to allow for aesthetic and creative potential, or for questions to be raised about why a given food is nourishing. But my initial interest was in what it would be to dismiss or diminish the role of meals, and meals more than food itself are my focus here. Meals are a contingent way of incorporating the project of nutrition into human life, something we could indeed 'reformat'. I feel moved to defend their importance. The line of thought developed below is a somewhat roundabout defence. By comparing meals and art, we can see them as two interestingly different extremes, where each extreme helps us meet a need for meaning.

This line of thought grows out of an earlier schematic argument, to the effect that meals cannot be art (John 2014). This claim perhaps has some controversial bite to it, given that, for example, meals have huge potential for aesthetic properties, cuisine is often referred to as an art, meals can be elaborately designed, and artists have made works aiming to have the structure and function of a meal (such as work by Rirkrit Tiravanija to be discussed below). My schematic argument was that meals are disqualified as art because meals are too capacious, involving the convergence of too many purposes, values, roles and unreflective processes (John 2014, pp. 258-260). I claimed that a necessary condition for art is that an artwork isolates something for our attention and response. Meanwhile, in a meal there is no element, not even the necessary element of food, that needs to be the centre of attention. I take this to be not a negative feature of meals, something that diminishes their value, but a reflection of the interestingly different relations to meaning and value that meals have evolved to have. This paper aims to extend this argument and more clearly articulate the contrast between meals and art.

The overarching contrast concerns how experience, understanding and appreciation relate. In the long histories of the things we call meals and art, this contrast may not be so clear, but I think it is a significant one now. Art aims to support an intimate relation between subjective experience, access to meaning, and appreciation: it is constitutive of art that assigning meaning and value to an artwork

\footnotetext{
${ }^{2}$ See Alexandra Plakias on how to define food, ruling out a purely nutritional approach (2019, pp. 1-8).
} 
should emerge from and be responsible to people's experience of the work. Although it is hard to specify what adequate appreciation of art demands, it would not make sense to let the meaning and value of artworks emerge independently of what adequate appreciators were able to make of artworks through experiencing them. Meals, on the other hand, help us to have recognizable, meaningful lives, but not because our experience, understanding and appreciation of meals give us particularly good access to their meaning. It is common for meanings to be assigned to meals that float free of the meanings that people experiencing meals could be expected to find in those meals. Meals are not well-governed intentional activities: they resist having a unifying point or meaning that meal-participants are responsible for grasping and that should guide meal appreciation. This is not a fault or deficiency in meals; my claim is that this possibility for divergence between experience and meaning is essential to the value of meals in human life. Art and meals manifest radically different but complementary routes to meaning, speaking to equally pressing human needs. One consequence of this view is that attempts to "turn meals into art' must fail. Such efforts mistake the basic contrast between meals and art that supports their respective value as generators of meaning.

This view is developed here by, first, discussing meaning claims made for meals, highlighting their indifference to integration of experience and meaning. The next section articulates and illustrates the relevant contrast with meaning claims for art. Then I consider a series of objections, some focusing on the meal-art relation and some focusing directly on meals' potential for unifying meaning. I conclude with some comments on the complementary value of these different kinds of meaning-making practices.

\section{Meals as Meaningful}

I begin with some examples and ideas from researchers who study meals. What is a meal, and what kinds of meaning can meals have? This is anthropologist Mary Douglas on what meals are:

A food event is an occasion when food is taken, without prejudice as to whether it constitutes a meal or not. A structured event is a social occasion which is organized according to rules prescribing time, place and sequence of actions. If food is taken as part of a structured event, then we have a meal (1982, pp. 90-91). ${ }^{3}$

${ }^{3}$ Douglas here credits these terms to Michael Nicod, but the precise source is not cited. 
Douglas takes a meal to be guided by rules that impose some structure on a given meal type and on the relations between meal types. If there is more than one meal in a day, the rules for the different meals, in terms of staples, quantity, qualities (e.g., hot/cold, eaten with utensils or fingers), and sequencing (e.g., savoury to sweet), relate to the rules for the other meal(s), by repetition, variation and simplification (Douglas 1982, pp. 92-98). A roughly structuralist conception of meals seems right: a meal is identifiable as such because it has a daily presence, with regular expectations for the food and for how it relates to any other daily meals. That meals are social food events also seems important; even if eaten alone, the expectations for meals are supported by the practices of a social group. This approach emphasises routine expectations for and differentiation of daily events; it does not establish a strict or clear way to settle how much routine is needed, how well expectations need to be met, and how differentiable the events have to be, to identify meals as opposed to food events.

Sheep seem to be eating steadily every time I see them. Is life one long meal for sheep, or do they never have meals because there is no differentiation, no possibility of relations between meals of the same and different types? I lean toward the "no meal' view of sheep eating. If one household has an occasional eating-whatever-isin-the-refrigerator event, taking place at least once a year, but in no particular season, involving no rules or expectations for what foods are eaten, occurring at any time of day, and with no larger socially recognized identity, that seems better cast as a food event. If I often have popcorn when going to the movies, that seems like a currently socially recognized pattern (popcorn with film), but there is no rule for eating popcorn in this context: it is too optional and irregular to be a meal. However, if there were a rare but welldefined occasion, with socially shared expectations for what to eat when ('Leap Year Day 29-Course Chow-down', 'First Failed Romance Feast'), that would have a much stronger claim to meal status.

Here is one example of Douglas proposing a meal meaning. In a study of early 1970's British meals, Douglas describes a "less significant meal, a tertiary food event consisting of a sweet biscuit and a hot drink" that can take place "at different times, say at 4 on return from the factory on weekdays, at bedtime on weekends" (1982, p. 91). She sees the following relation between the main Sunday dinner pudding, the cake at early evening tea, and the Sunday night biscuit: 
When it comes to the final course of the main meal or the last meal on Sunday night, the range of sweet biscuits reveals the pudding again, in its most desiccated forms: currant biscuits, sugar-coated biscuits, jamcentred biscuits. Nowhere else in the world is there a steady demand for small geometrically shaped sweet biscuits with a layer of jam or cream in the middle and coated with icing, at a sufficiently modest price to permit them a regular place in the daily menu. In so far as the sweet biscuit eaten last thing at night on Sunday is a dry version of the cake, and the cake a dry version of the pudding, we can regard it not merely as a coda, nor as an irrelevant conclusion, but as a summary form, literally, of those courses. The biscuit is capable of standing for all the sequences of puddings through the year and of wedding cakes and christening cakes through the life-cycle (1982, pp. 96-97).

As a relative newcomer to British life, I found this claim very interesting. It highlighted something I had wondered about - the ubiquity and variegated forms of dry biscuits - and gave them a role in upholding larger patterns of daily life. I do not know how to confirm such a claim (and the role of the biscuit may be fading). However, I would not take this claim to be disconfirmed by the fact that British biscuit-eaters would deny that biscuits play this role, perhaps saying that a biscuit with cocoa on Sunday night is simply a nice treat. I think it is possible that biscuits in Britain are a desiccated, visually articulated symbol of more rich, messy and celebratory food events. But no one has to experience this meaning in dunking a biscuit in cocoa. It would be weird and possibly subversive of that meaning if they did. This example gives us a glimpse of the issue: the possible divergence of meal experience and meal meaning.

Roy Strong's history of feasting practices from ancient Mesopotamia to modern Europe documents medieval European observance of the Benedictine Rule, which required, for instance, no conversation (though a text was read aloud during the meal). At an 1lth century abbey,

[the abbot] ate alone, and was provided with more sophisticated dishes and better wine. [...] Monks washed as they entered the refectory and sat in a prescribed order. [...] No one started to eat until grace had been said and the abbot gave the signal. This was the meal as a form of spiritual communion, with the mind lifted heavenwards by the text being read aloud, away from any consideration of what was being eaten (2003, p. 52).

At a Cistercian abbey around the 12th and 13th centuries, 
The etiquette was strict and any breach of it called for the offending monk to prostrate himself on the step of the high table until the prior tapped his knife bidding the monk to rise. [...] Fingers and knives should be first wiped on a piece of bread and then on the tablecloth; salt was to be taken on the tip of the knife; nothing was to be passed without a mutual bow of respect (2003, p. 54).

Strong also quotes a 12th century visitor to an abbey, reporting that monks at meals were "gesticulating with fingers, hands and arms, and whistling one to another in lieu of speaking, all extravagating in a manner more free and frivolous than was seemly" (Giraldus 1937, p. 70; quoted at Strong 2003, p. 45). The monks had found a way around the rule of silence.

Leaping forward to the 1980's, Joanne Finkelstein argues for a critical interpretation of urban restaurant dining in the United States. She begins her account of 'dining out' by sketching what she takes people ordinarily to assume about this practice:

Commonly, dining out is seen as an expression of one's individuality: we choose to dine out, there is no compulsion to do so; we select a restaurant with food that appeals to our palate and which is within our price range; the event can summarize our knowledge of food and interests in pleasure, status, fashionability and entertainment $[\ldots]$ it can be regarded as a demonstration of what we value and desire.

The argument of this study is that the styles of interaction encouraged in the restaurant produce an uncivilized sociality. The artifice of the restaurant makes dining out a mannered exercise disciplined by customs that locate us in a framework of prefigured actions. Dining out allows us to act in imitation of others, in accord with images, in response to fashions, out of habit, without need for thought or self-scrutiny. [...] it must be considered a practice which weakens our participation in the social arena, even as it appears to increase that participation. (1989, pp. 4-5).

Having noted such things as that we ignore the conversations and presence of people in close proximity to us in a restaurant, Finkelstein thinks restaurant dining suppresses the possibility of facing "improprieties, accidents and challenges to the habitual" and allows us to "embody blunted sensibilities" (1989, pp. 104-105). Finkelstein takes the modern restaurant diner to unwittingly accept as a norm of dining out a suppression of sensitivity to social life.

Finally, in a book about Mexican and Mexican-American food experience and practice, Meredith Abarca presents interviews with 
people about memories of food and eating. This is an excerpt from her interview with Licha, a kind of aunt of Abarca's, who grew up in Michoacán. ${ }^{4}$

Licha: We didn't have a lot of things, but we were not hungry. My mother was very resourceful to figure out what to cook. [...] My mother was one of those people whose salsas are always delicious. What did she put in it? I think all the love in the world, so that she could feed so many $[\ldots]$

Our table, well nowadays I have seen tables scraped that back then I thought ugly, but now they are expensive.

Meredith: Now they are in fashion. The country, rustic look.

Licha: Yes. We didn't have chairs. We used a bench. Everything was rustic back then, and we didn't appreciate those things, right? But now I would want to have those benches and table. [Ah] those tablecloths [hand-embroidered], I am telling you, were so beautiful. But understand that my mother did not go to school. She was born and died illiterate. But she never let anyone to come to the table naked; they had to at least have a tee shirt. She would say that food was blessed. She would ask, "What do you ask God when you pray a Holy Father?" She would answer, "to give us our daily bread". So she would say that we needed to come to the table with respect. Thanks to God, we were never hungry because my mother was muy luchona [a fighter] to make food.

Meredith: What kinds of food would she make?

Licha: Well, back then we had quelites for breakfast.

Meredith: What are quelites?

Licha: Some weeds that used to grow in the fields. ${ }^{5}$ That now, as my mother said, "everything ended with the concrete". Also, now with so much insecticide used for other things, to some degree it has ruined the vegetation in Apatzingán (2006, pp. 166-167).

The adult Licha here remembers and interprets her childhood meals using various perspectives she has acquired over her lifetime.

I will draw two simple points from these examples, not doing justice to their individual suggestiveness. First, these accounts take up quite different perspectives on the meals under consideration to

\footnotetext{
${ }^{4}$ Abarca says that she has inserted a few words in brackets to complete or explicate what Licha said.

${ }^{5}$ 'Quelites' is used to refer to a number of edible wild greens, such as amaranth and hoja santa.
} 
capture what is significant about them. As Licha's memories show, a meal can hold personal memories of being loved, a record of an individual's strength and achievement, and it can mark religious belief, economic and educational status, and changes in foodstuffs, agriculture, and environment. A meal can be viewed from a sociological distance as a conflicted mixture of individual self-expression and collective failure of social responsibility. The historian can study meals as imposing an ideal of religious order and reverence for God, and the anthropologist can see it as a formally structured symbol of a secular culture. In all of these accounts, of course, the meal is also marked by forms of aesthetic experience and possibilities for aesthetic judgement (the ugliness of a table, a restaurant's cuisine, qualities of wine, and shapes of biscuits). These give some sense of the capaciousness of meals with respect to kinds of significance.

Second, these accounts do not attempt to claim coherence with - or to resolve disparities between - how a given person participating in such meals would experience them and the claims made to capture their significance. Licha's account of her childhood meals makes this disparity explicit at points, as she notes that as a child she found the now-desirable table and benches ugly, and one can speculate that the beauty of the embroidery was of little interest to children eager to eat or was perhaps not even visible to them as beauty. That her family's meals showed her mother to be a fighter was, I would guess, not what the children or mother would have understood about those meals, even if, as seems plausible to me, it is one thing those meals meant. In the case of the monks following the Benedictine Rule (or creatively working around it), presumably the individual monks had to conceive of their behaviour as conforming to rules for reasons - such an understanding of the meal would have informed their experience. But it seems unlikely that the sense that the historian and temporally remote student of these practices might have - that this was an unusually ambitious imposition of control and religious meaning onto eating practices, suppressing possibilities for pleasurable human exchange - would have been accessible to the monk at his table. Or at least, it is not necessary that the controlling aspects of these meal practices had particular prominence in the monks' experience for those functions to be important to understanding the Benedictine meal. For a given monk, mealtime could have been salient in the day for the pleasure of satisfying hunger and thirst, for getting a respite from work, or for daydreaming rather than attending to scripture. The historian Strong himself interprets the monastic meal in terms of its legacy for secular etiquette, as 
he sees it as having entrenched "attributes essential to the evolution of table manners" (Strong 2003, p. 52). Finkelstein's argument explicitly asserts a divergence between what the modern restaurant diner thinks she is doing (participating in the social realm in an individually expressive way) and what she is doing at a deeper level (avoiding genuine connection with social others, accepting and failing to examine social norms). As noted above, the hot drink and biscuit meal, on Douglas' account, seems unlikely to have the meaning she ascribes to it in the experience of people reaching for the kettle and biscuit tin on Sunday night.

Let me grant that the claims for meaning assembled here may not be uniformly compelling. And I will not say much about justification or proof - what does it take to show that a meal or meal practice has a proposed meaning? My purpose here is not to defend specific meaning claims. It is rather to say that there is an interesting lack of concern for joining up what it might be like to participate in and experience these meals and the substance of the meaning claims. It seems acceptable to attribute meanings to meals from a wide range of sources: economic and institutional structures that affect the aspirations of the participants, widely but perhaps only inchoately held religious and civic beliefs, and patterns of behaviour that may only 'pop out' as interesting patterns from a comparative or historical distance. From what vantage point can we see the significance of having only men at the table, using hand-decorated linens, or having multiple restaurants to choose to dine at? These forms of meaning have to have some anchor in how people participate in and conceive of their meals, but such meanings need not play a dominant role in what meal participants think, feel, notice, like and dislike about their meal practices. Roughly, putative meanings aim to link features of meals to ideas about what explains those features (e.g., economic status, a parent's love and determination, environmental and agricultural context) and to larger significant patterns those features contribute to (relation or distance between social groups, aesthetic and celebratory traditions, religious and ethical self-conceptions). A meaning claim will try to answer a question about meal features, perhaps illuminating the interests they served or social norms they entrenched. Perhaps a meaning claim has to help to distinguish a given meal practice perspicuously from other practices. But participants do not have to be able to trace the features they recognise back to those meanings. Finkelstein can point out to me that I indeed ignore the restaurant diners at the next table, and this gives her an anchor in 
the features of restaurant meals for assigning them significance. Perhaps it is relevant to her argument that, once this feature is pointed out to a diner such as me, I find her claim provoking - I cannot immediately reject the idea that my pleasure depends somehow on blunting my concern for the people around me. So I grant that, for some meaning claims, it may be appropriate to require that the claims register as potentially illuminating to meal participants, but that is still not to require that the meals, as ordinarily lived through, are or could be given that meaning. ${ }^{6}$

\section{Art as Meaningful}

Now let us think about art. As forecast above, I take art to assume a different relation between experience, understanding and appreciation. I speak about art broadly, risking oversimplification in order to make the intended contrast with meals clear. With a work of art, we should aspire to appreciate it in a way that is built on understanding it, and this understanding is responsible to the experience made available by the work. The experience is necessary to the understanding and appreciation of the work. Perhaps this understanding is not always helpfully summed up as a grasp of 'meaning', but nonetheless, appropriate acknowledgement of a work's artistic elements, based on experience of and attention to whatever makes it 'tick' as a work of art, is required for appreciation. This is almost too obvious to have to say. I take it to be one of the ideals behind the making and experience of art: artworks are things we try to experience and know well. An appreciation that does not emerge from this experiencebuilt understanding - say, it rests on never having experienced a work, or on having encountered it under misleading or impeded circumstances - is inadequate. Arguably, appreciation without experience of a work is impossible. Granted, there does not seem to be such a thing as knowing an object completely or perfectly, but the practice that has arisen around art involves a kind of regulative ideal, aspiring to have appreciation be grounded as fully as possible

\footnotetext{
${ }^{6}$ Do my claims about meal meaning call for different terminology, e.g., meal 'significance' rather than 'meaning'? Stecker uses 'significance' to refer to something slightly different (contingent meaning for a given audience), but he also distinguishes significance as 'by definition not something that everyone must take into account to understand or appreciate a work, or it would be part of the meaning' (Stecker 2003, p. 76). I leave this question open, admitting that sharper terminology might be helpful.
} 
in relevant experience and understanding. ${ }^{7}$ The ideal regulates not only the aspirations of the audience, but the possibilities for artistic elements, as artists cannot give works artistic elements that are, in principle, inaccessible and unknowable. Any such features that people experiencing the work could not come to know of would not be artistic elements. A sculptor can now use the known radioactivity of a sculpted substance as an artistic element, but that would not have been possible in most of artistic history. ${ }^{8}$ Examples sometimes given of non-artistic elements that are knowable, but seem unable to show up as relevant to appreciation, are a work's economic value, the colour of the canvas on the back of a painting, and the font used in a given printing of a novel. ${ }^{9}$ Their status as 'non-artistic' signals the assumption that audiences cannot draw on these elements in understanding and appreciating a work. Artists can of course challenge assumptions about what is not an artistic element. What they cannot do is make a work with artistic elements that, for whatever reason, cannot be found relevant to its appreciation.

I doubt I can give a satisfying account of 'artistic elements', but let me at least sum up what I want this notion to do. ${ }^{10}$ Artworks aim to offer an experience with a point that can be appreciated. Though 'the point' need not be a single message or fixed meaning, there should be something audiences are asked to notice, think, feel, or try to do in their experience of the work. The artistic elements are whatever features and resources can be found and understood by a work's audience to support this project. Supporting this project does not mean ensuring that the work is successful or good; it just means being relevant, and able to be understood as relevant, to audiences doing what the work offers. There is a circularity here: we do not first establish what a work's artistic elements are - what can be found to matter to its appreciation? - and then establish what it specifically

${ }^{7}$ Mothersill discusses the difficulty of specifying conditions for adequate, albeit not complete knowledge (1991, pp. 331-335). Irvin (2015) considers poetry that makes it difficult to grasp what is to be known and understood in a poem, but still asks for experience-based understanding.

${ }^{8}$ See Arnot (1999) on artist James Acord.

${ }^{9}$ Robert Stecker notes, "artistic value is typically connected to the understanding of a work via the experience of it [...] [This typically precludes] value in no way tied to the experience and the understanding of the work, such as monetary value, from being artistic value" (2010, p. 194).

${ }^{10}$ See Stecker's way of addressing a largely overlapping issue. He offers a test for identifying properties that contribute to artistic value: "knowing or recognizing that the work has the valuable property requires grasping the work's meaning" (2019, p. 52). 
offers. There is rather a negotiation between sizing up what the work seems to offer (roughly, what it asks an audience to think, feel or do) and taking on board the features and considerations that seem relevant to making that offer. Kendall Walton, discussing how we arrive at appropriate categories for perception of art, describes such a negotiation, incorporating as well testing for how a work can be enjoyed:

The process of trying to determine what is in a work consists partly in casting around among otherwise plausible ways of perceiving it for one in which the work is good. We feel we are coming to a correct understanding of a work when we begin to like or enjoy it; we are finding what is really there when it seems to be worth experiencing $\left(1970\right.$, p. 359). ${ }^{11}$

Tying artistic elements to what can be found relevant to appreciation of a work opens the door to variation in what different audiences are capable of experiencing and understanding and hence of identifying as artistic elements. That seems right; the goal here is not to demand that there be an authoritative, fixed answer for every work - what is relevant to understanding and appreciating this work? but to say that artworks aim to support appreciation that is built on experiencing something with understanding.

Aesthetic theorists articulate different versions of this relationship. For Malcolm Budd, "the basic way of determining the value of a work of art requires you to experience the work with understanding" (Budd 1995, pp. 11-12). Mary Mothersill says, "To be appreciated, music must be listened to but also heard; paintings must be looked at but also seen; poems, not only read but understood" (1991, p. 324). And "To see whether a particular item pleases you, it is necessary (truistically) to 'get to know' the item [...]; what is called for [...] is the knowledge that comes by acquaintance" (1991, p. 331). Richard Wollheim claims the term 'criticism' for "the process of coming to understand a particular work of art" (1980, p. 185) and presses the need for experience informed by background knowledge: "Part of

\footnotetext{
${ }^{11}$ Walton's account of the categories of art, and their role in determining the status features have in experience of works in a given category (as standard, variable, or contra-standard features), is an account of how categories help guide us toward specific artistic elements (1970, pp. 339-342). The fact of there being a category of art, encapsulating such guidance, seems to rest on a lot of prior exploration into what can serve as an artistic element at all (what can show up to beings like us as relevant to experience and understanding, what can be expressive, meaning-bearing, or experientially consequential?).
} 
coming to understand a work of art is learning how to perceive it, where this is over and above taking perceptual account of everything that is there to see" (1980, p. 197). Jenefer Robinson offers an ideal of emotional experience and interpretation for a given genre of art, realist literary fiction: "[O]ur emotional experience of the novel or play is itself a form of understanding [...] if I laugh and cry, shiver, tense, and relax in all the appropriate places, then I can be said to have understood the story" (2005, p. 123).

To illustrate briefly, I have chosen a few artistic examples which happen to include the representation of meals. Judy Chicago's 1979 mixed media, large-scale installation The Dinner Party uses porcelain tiles and dinner settings at a table to name and evoke 1,038 women in Western history. One commentator, noting that the "honorees at the dinner table itself are symbolically represented through elaborate needlepoint runners, in large part worked in techniques drawn from the period in which each woman lived", takes Chicago's use of various media associated with women's domestic labour to produce "an explosive collision between aesthetics [...] and the domestic kitsch" (Jones 2005, p. 410). ${ }^{12}$ Another account of The Dinner Party discusses the needlework for specific place-settings:

The runner for Petronilla de Meath, a fourteenth-century Irish woman tortured and burned as a witch, is a Celtic interlace pattern executed in couched fleece and wrapped cords to create a high relief; the strong interlace design also comes up and invades the area of the table and appears to attack and engulf the plate (Withers 1992, p. 458). ${ }^{13}$

It is relevant to appreciation that the needlepoint style and design strive to convey the historical and feminist significance of the person remembered; an appreciator should aspire to experience and understand this aspect of the work. Meanwhile, I hope it sounds right that the people eating at Licha's mother's table need not, and possibly should not, have experienced the historically fitting embroidery to be significantly characteristic of their meals.

Meals show up as important to assessing the prospects for human connection in Guadalupe Nettel's novel After the Winter. Two

\footnotetext{
${ }^{12}$ See information and images of The Dinner Party on the Brooklyn Museum website, which holds the work: <https://www.brooklynmuseum.org/exhibitions/ dinner_party.>

${ }^{13}$ Images of this place setting are available on the Brooklyn Museum site. $<$ https://www.brooklynmuseum.org/eascfa/dinner_party/place_settings/petronilla_ de_meath $>$
} 
scenes concern the eating and drinking that takes place in one character's rather monastic apartment. Claudio reports proudly on the unadorned simplicity of his home life: "I ingest my sustenance quickly, standing up by the other window, which, as I said before, also looks out onto a wall" (Nettel 2014, p. 19). Perhaps Claudio is a likely customer for Soylent. Later in the novel, Claudio's ill-fated relationship with Cecilia is exposed pointedly in her attempt to make a lovingly prepared meal in that apartment: "The moussaka bubbled calmly away in the oven, giving me time to lay the table and create a romantic atmosphere with the light of a candle [...]" Claudio never appears, and Cecilia's "hunger and misgivings spiralled out of control. I finished the bottle of wine and angrily devoured the salad, followed by the main dish" (Nettel 2014, p. 170). Though separated by many pages in the novel, the reader can and ideally should compare the representations of the two meals, as emblematic of the mismatch of these people. That these passages in the novel have such meaning implies that readers have access to and responsibility for grasping it.

Finally, in a book devoted to Leonardo da Vinci's The Last Supper, Ludwig Heydenreich tries to identify the elements that give the painting its power:

And here we note another curious thing: the orderly arrangement of the objects on the table in front of Christ; immediately to the left and right of him they begin to fall into disarray. Thus the space before the Lord is prepared, so to speak, for the sacred action which Christ - rising above the wave of emotion still seething round him among the disciples - is making ready to accomplish [...] (1974, p. 63)

Goethe, discussing the painting, gives careful attention to the disarray, focusing on the depiction of Peter and Judas:

Holding a knife in his right hand, he accidentally, and without design, touches with the handle of it the side of Judas, by which the attitude of the latter, who is stooping forward, as if alarmed, and by this motion overturns a salt-cellar, is happily effected (quoted in Heydenreich 1974, p. 88).

Meaning is given to the finely depicted action and disarray. ${ }^{14}$ These

${ }^{14}$ Goethe hopes that his reader can see these details by referring to an 1800 engraving of the painting by Raphael Morghen. See a public domain image of it on the Metropolitan Museum of Art website: <https://www.metmuseum.org/art/ collection/search/715639> 
details in actually occurring meals are mostly unnoticed and mostly should go unnoticed. If there are persistent patterns of order and disarray in an ongoing meal practice, that may well hold some meaning as to the social and aesthetic goals of the practice, but it is the enactment of the order or disarray that would be meaningful. The experience and understanding of it would be either unnecessary or possibly disruptive of its meaning.

\section{Objections to the Contrast}

So far I have pressed a contrast between the bases for ascriptions of meaning to meals and art. Meals, like artworks, offer complex forms of experience and can hold complex meanings. The interesting contrast with art is that there is no demand for coordination of these elements in meals. In particular, the fact that those who experienced a meal did not, and perhaps could not, have understood it to have a certain meaning would not defeat the claim for such meaning. Meanwhile, experience of art embeds a demand for this coordination: audiences for art are asked to integrate their experience and understanding of a work, coming to know what is relevant to its workings as art, and furthermore to appreciate it on that basis. Let me briefly consider three objections to this contrast.

First, one might say that I am failing to acknowledge an important similarity between meals and art, in that there is no one experience of them that is authoritative. I have emphasised the huge variability in how people can experience meals; I have underemphasised that fact about works of art. People experiencing a work of art can find different, and different kinds of, meanings in it. Nonetheless, the claim I want to highlight is that as audiences for art we share a commitment to a basic project: we try to have our experience of the work incorporate a full understanding of its artistic features and try to appreciate it on that basis. The fact that the individual pursuit of this project leads to interestingly different outcomes is consistent with us doing the same thing at a functional level, seeking to integrate our experience, understanding and appreciation of a work. Responding to a work of art gives us that responsibility, and a given person's appreciative response to a work can be challenged and improved by learning more about it and experiencing it anew. My claim is that this is not a project that we share in meals. There are many things to understand about a meal or meal practice, and what those experiencing the meal make of it is one possible focus of understanding. But the participants themselves are not responsible 
for experiencing and understanding the meal; they are free to ignore, misunderstand, and idiosyncratically dwell on features of the meal. Perhaps we sometimes would like to cast such participants as obtuse or nä̈ve (as I think Finkelstein does with modern restaurant diners), but we cannot legitimately criticise them for failing to understand the meaning of their meals - that is not our responsibility to a meal. Let me grant that we often have responsibilities (e.g., to family members, to guests, to moral ideals) that apply to us in our participation in a meal: such responsibilities are one source of the meanings that meals can have. However, flouting those responsibilities or failing to recognize them in one's participation in a meal is better conceived, in terms of how meal meaning emerges, as a behaviour that could add to the capacious accretion of meal meanings (e.g., meal as site of rebellion or manifestation of familial dysfunction), than as a failure to meet a responsibility to understand the meal's meaning. Participants' experience and understanding of meals are more radically untethered to a shared project than our individual attempts to experience artworks with understanding.

Second, a more powerful worry is that I ignore another fully parallel fact about art practices, that art too can be studied from a multitude of perspectives - historical, sociological, economic - that will not invoke individual art experience and that can claim to show the meaning of those practices. We can pursue understanding of art by considering, say, the sexism that supported a conception of male artistic genius, the role of aristocratic patronage, or the impact of technology on artistic possibilities. How is this any different from the multiplicity of forms of meaning and understanding that can be assigned to meals? Let me grant, first, that art and meals are similar in this way. The domain of art-making and experience is open to study and interpretation as a meaningful human practice, and the kinds of meaning one thereby assigns to the practice need not emerge from or strive for a coordination of artwork experience and understanding. What is distinctive about art is that such a coordination in response to a given work is expected and aimed for within the practice, and the kind of meaning that has this coordinating role, in an experience-understanding-appreciation nexus, has a privileged status. That such meaning is aimed for helps to constitute a practice as an art practice; such a nexus has no privileged status in constituting meals. Meals are very rich accumulators of meaning, but there is no privileged form of meaning-generation (including no first-personal, experiential-understanding constraint) that characterises them as meals. Meanwhile, although I will not try to 
defend this claim, it seems plausible to me that even a relatively 'remote' meaning claim about an art practice (e.g., concerning the political meaning of art institutions, not directly appealing to what an audience can experience and understand) will be most illuminating if it in some way adverts to that core project of experiencing and appreciating works with understanding. An account of how an art practice has political meaning, for instance, will be better anchored in the practice to the extent that it acknowledges the basics of what people do with art.

Third, the companion objection is that meals can indeed incorporate the aspirations for integrated experience, understanding and appreciation that I have assigned to art, and that this integration can have a comparable privileged status. The objection depends on finding compelling examples. Here I mention just a few, and I do not respond to any of them fully adequately - these are interesting, difficult cases. First, consider works by contemporary artist Rirkrit Tiravanija, in which he arranged for (and in some cases cooked) food to be served to gallery visitors, for free. Here is a Museum of Modern Art description of one of these events:

In 1992, Rirkrit Tiravanija created an exhibition entitled Untitled (Free) at 303 Gallery in New York. This landmark piece, in which the artist converted a gallery into a kitchen where he served rice and Thai curry for free, has been recreated at MoMA as part of the installation Contemporary Galleries: 1980 - Now on view on the second floor. This back office curry kitchen has been replicated to scale, and the artist worked with MoMA to recreate the experience, with curry prepared and served by the Museum's restaurant staff daily from noon- 3:00 p.m.

In this deceptively simple conceptual piece, the artist invites the visitor to interact with contemporary art in a more sociable way, and blurs the distance between artist and viewer. You aren't looking at the art, but are part of it - and are, in fact, making the art as you eat curry and talk with friends or new acquaintances (Stokes 2012).

Tiravanija aims to have people share food in a sociable way, and that indeed sounds like a meal. However, I think this food event attempts to transform the practice of having a meal, which does not require engagement with its own meaningfulness, into an event in which one's experience is in the service of artistic meaning. The gathering over food in an art gallery is intended to provoke consciousness of and reflection on the conditions for sociability. For me this is a crucial and narrowing transformation, and I am willing to call this art, but not a meal. Writing about Tiravanija, art historian 
Claire Bishop notes that such works are often understood in terms of Nicolas Bourriaud's 'relational aesthetics': "relational art works seek to establish intersubjective encounters [...] in which meaning is elaborated collectively" and "viewers are not just addressed as a collective, social entity, but are actually given the wherewithal to create a community" (2004, p. 54). "This DIY, microtopian ethos is what Bourriaud perceives to be the core political significance of relational aesthetics" (2004, p. 54). I want to highlight the way Bishop and Bourriaud discuss these works: When confronted by a relational art work, Bourriaud suggests that we ask the following questions: "does this work permit me to enter into dialogue? Could I exist, and how, in the space it defines?" (Bishop 2004, p. 64, citing Bourriaud 2002 , p. 109). Bishop worries that "The quality of the relationships in 'relational aesthetics' are never examined or called into question. If relational art produces human relations, then the next logical question to ask is what types of relations are being produced, for whom, and why?" (2004, p. 65). Bourriaud and Bishop disagree about how to answer these questions, but they agree that a work such as Tiravanija's Untitled (Free) poses them and that in engaging with the work we should try to answer them.

I assume here that this line of thinking is at least appropriate in responding to Untitled (Free). The question of the work's political significance, and the idea that there is a demand to assess the relations the work supports, are perfectly at home within art practice. An artwork can even "seek to establish intersubjective encounters", but a meal cannot be held to such a fixed purpose. A meal may build a relation between people, but that it ends up having that significance does not hang on that goal having been the intention behind it, and it is not what meal participants are responsible for considering or understanding about it. 'Appropriately engaging' with a meal is not really a well-governed intentional activity - aside from taking in some food in a socially patterned way, there is not much asked of us in terms of achievements sought or questions posed. I take Tiravanija to be aiming to incorporate that ill-governed life activity into an ambitious construction of meaningful art. It may be interesting as art, but it does not safely transfer the sprawling life activity into the reflectively focused artistic context.

Let me note that while my discussion of meals has a descriptive aim, trying to identify something there to be found in meal practices, I am also trying to uphold this way of distinguishing meals and art. I take the 'ill-governedness' of meals to be extremely important to their value; if our ways of eating evolved in the direction of art - e.g., 
toward eating as a reflective performance of meaning - we would have lost a tremendously fruitful way of generating and embodying meaning. From this perspective, it is good that meals and art are a kind of 'oil and water' pair. ${ }^{15}$ I will return to the value question briefly at the end.

Am I ignoring the fact that people do have intentions for meals, such as, obviously, intentions for sociability? What is the difference between the meal I host, intending to enable participants to create a temporary community, and the event at which people gather to eat Tiravanija's curry and rice? One difference is that the intentions of even the host of a meal do not have particular weight or authority, as the intentions of an artist do, with respect to initiating and constraining potential for meal meaning. The host's intentions will jostle with multiple other projects and processes embodied in the meal, including possibly competing intentions of other meal participants - I cannot make forming a sociable community be the point of a meal, as much as I might want to (see the case of the romantic dinner below). More pertinently, I cannot make triggering some kind of reflective awareness of my intention be essential to participation in the meal; guests who give no thought to meals as occasions for sociable connection do not thereby fail to participate in them adequately. However, the gallery visitor who eats the free lunch without realising she is participating in an artwork will have no access to the questions it poses and will to some extent fail to experience and understand it appropriately.

A related, possibly harder case is the Japanese tea ceremony. It seems to combine an ongoing social and cultural practice with very deliberate aesthetic focus and reflection. Yuriko Saito pinpoints the difficulty of categorizing the tea ceremony:

Though many of its ingredients are works of art in their own right, such as a tea hut, a tea garden, a tea bowl, a flower arrangement, [...], the possibility is limitless for including other elements. They include the weather condition, bird's chirping, the sound of rain hitting the thatched roof of the hut, the spontaneous conversation between the host and the guest, $[\ldots]$ the smell and taste of the tea and snack, $[\ldots]$ and the slurping sound when we take our last sip from the bowl. $[\ldots]$ while there are strict rules governing the minute details for every aspect of the ceremony, the actual ceremony itself is unscripted, subject to the spontaneous convergence of various events and phenomena $[\ldots]$ (2007, p. 34).

${ }^{15}$ Thanks to Paloma Atencia-Linares for pushing me on this point. 
Along with the spontaneous inclusion of whatever details happen to strike the participants, there is the fact that the tea ceremony "consists of the most mundane and practical activity [...] drinking tea and eating a snack" (Saito 2007, p. 34). I am happy to defer to Saito's view of this practice, which is that it is indeed an art form. She links it to work such as Tiravanija's that "poses an inescapable dilemma for the artists trying to capture the everyday" (2007, p. 39). With the tea ceremony or Tiravanija's curry, "we are made even more aware of the difference between our eating experience as a part of a work of art and our everyday eating experience"; with these encounters "we cannot but be conscious of our participation in an art work" (Saito, pp. 38-39, 40). Saito is not directly concerned with denying that these are meals, but she does distinguish the artworks firmly from ordinary meals. The point I hope to draw from Saito's argument is that, if the tea ceremony asks participants to focus on their experience within a self-conscious, knowledgeable project of appreciation, the practice constrains participants in a way that - on my view - meal participants cannot be constrained.

Finally, consider two examples that raise problems independently of the meals-art relation. First, the Passover seder seems to have an essential identity as a meal, and it seems participants in the seder have a responsibility to understand the carefully focused meaning that the meal has within the faith and practice of Judaism. ${ }^{16}$ Or, second, suppose you are participating in a romantic dinner: it seems that, similarly, you would have a fairly well-governed role that would include experiencing the romantic meaning of the meal. ${ }^{17}$ Why is it not obviously true, given such examples, that meals can share with artworks both a focused, meaning-bearing identity and the aspiration to coordinate experience, understanding, and appreciation? My responses to these examples are somewhat different because their sources of meaning, and the authority of those sources in relation to participants' experiences, are so different. The Passover seder, as a yearly ritual within the Jewish tradition, has meaning that is

\footnotetext{
${ }^{16}$ E.g., a seder includes the explicit asking and answering of 'why' questions concerning the foods eaten and actions carried out during the meal. There is substantial variation in seder practices, but for purposes of this argument, we could focus on a scrupulously followed exemplar. An Orthodox Jewish Hasidic website says: "Each item has its place in a 15-step choreographed combination of tastes, sounds, sensations and smells that have been with the Jewish people for millennia" (Chabad.Org, "What is a Seder?").

${ }^{17}$ These examples and the many issues they raise were pressed by Aaron Meskin and David Fajardo.
} 
intended to be accessible to and experienced by even the children who participate. But what seems distinctive about the seder is that the meaning comes first, as it were. The meaning is settled, and it is expected to be coordinated with participants' experiences, but the experiences themselves cannot guide or challenge the meaning. If I happen to find the fruit-and-nut charoset on the seder plate to be a delicious, indulgent treat, that would not challenge its significance within the ritual - I could not use that experience to contribute to my understanding of the seder's meaning. The seder takes up the foods and activities of a meal and fully absorbs them into a celebratory religious ritual. As an authoritative ritual, the goal of having participants' experience support meaning is present, but the lack of coordinating experience does not threaten the meaning. Within the terms of this argument, the seder has some similarities to Tiravanija's work (harnessing the foods and activities of a meal within art or within a religious ritual), and it stands in complex relations to both Christian communion (in which a ritual involving symbolic gestures with bread and wine seems to have pushed out any claim to meal status) and the Benedictine-rule-guided meal mentioned earlier. The latter practice was designed to have a devotional function and to promote reverence and obedience, but this meaning is relatively diffuse and suited to daily repetition and variable conditions. The Benedictine meal, despite its extensive control of behaviour, is a meal in my terms rather than a ritual; it is a social food event with more open potential for interpretation. My tentative claim, then, is that the seder's identity as a ritual, with a ritual's given meaning, is dominant, and its way of relating experience and meaning is neither that of a meal nor a work of art. The meaning of this food event as a ritual within Jewish tradition holds authority over whatever the participants may be experiencing. However, if we conceptualized the seder as a meal, even its meaning within Jewish tradition would be just one meaning to be found in it (and would be open to being jostled and rivalled by other meaning-bearing factors).

With that view of the seder in mind, I hope the romantic dinner is easier to situate. The romantic dinner aims to harness a meal for the purpose of affirming and savouring a love relationship. The sharing of good food in pleasant circumstances is intended to be saturated with the mutual awareness of being people in love; ideally, the romantic meaning of the meal is experienced by the participants. Unlike the seder, it seems that the experience is indeed necessary for the meal to have this meaning: there is no authoritative tradition that can endow a putative romantic dinner with romantic meaning if 
one or both participants fail to 'feel the love'. This seems to place the romantic dinner closer to the artwork, if the meal's meaning has to coordinate with experience in this way. However, I hope it is also clear that the romantic dinner, even if it has this aspect in common with artworks, does not place a demand to integrate experience and meaning on the meal participants. There is no such demand. It is a happy occurrence when the people involved do in fact affirm and savour their love in sharing a meal. But often they do not, and that is as it should be, in a sense, if what they are participating in is really a meal. A meal cannot require that you think or feel a certain way, and a romantic dinner, as a dinner, cannot require this. Coming at this from a different direction, one might say that the participants are only responsible to the romantic meaning of the event if they want to be, while both the seder and the artwork have, for different reasons, ways of making us responsible to meanings, even to ones that we may not want to affirm.

\section{Concluding Comments on Needs for Meaning}

I have sketched here what I think of as two extremes. On the one hand, we have an art practice in which we try to know something fully and try to experience and value it on that basis. On the other, we have a meal practice in which knowing the thing fully can be nearly or genuinely impossible for the ones who experience it, and for which the meaningfulness of the thing is allowed to float free of their experience. Why might we need both kinds of practices? I will conclude by speculating about what strikes me as a complementary relation between the two kinds of meaning-supporting practices.

This speculation concerns what Richard Wollheim called leading the life of a person. Citing Kierkegaard's remark about life having to be understood backward but lived forward, Wollheim says, "Kierkegaard is right. Living a life, understanding the life one leads, are different, and there is a possibility of conflict between them. The attempt that a person makes to understand his life may interfere with leading it" (1984, p. 162). However, Wollheim only partially endorses this contrast, taking it to be commonly exaggerated and misunderstood. In his account of leading the life of a person, there is an important role for looking backwards and seeking understanding, where this is centrally a process of self-examination: "the question that he asks himself will naturally be of the form, Is this what I really desire? Do I really believe that?", where this questioning "is required not only by his situation but if he is to lead the life 
of a person" (1984, p. 166). I find the idea that introspection and self-interpretation are characteristic elements in the life of a person to be compelling. But Wollheim's focus on introspection and selfinterpretation is too strong; the putative life of a person based on achievement of this kind of self-reflective agency would be unrecognisable and unliveable.

One reason it would be unliveable is that it is impossible to have beliefs, desires and intentions that would apply to and comprehensively guide one through the waking hours of a life. It would be paralyzing if I had to 'really desire' and 'really believe' something relevant to every bit of my activity. It often does not matter precisely what I do, but I have to do something. Supposing that I have a belief and a desire that lead me to eat soup with a spoon, that leaves it quite open whether I have one spoon or numerous differentiated spoons, and it certainly does not specify putting a soup spoon on a table to the right of a knife, to the right of a bowl. ${ }^{18}$ That is what I do, and competence in getting through a day is in part to have acquired such habits without evaluating and affirming them. The pattern of meals that a person participates in is a wonderfully unreflective settling of innumerable details that have to be settled somehow on a daily basis.

Second, insignificant as something like spoon-laying behaviour is in isolation, it contributes to a pattern that marks me as belonging to a culture and a historical period. It is a tiny, concrete element that helps to make my life recognizable as a given kind of life. A person cannot sustain a life using the resources of introspection and self-interpretation alone (as I am sure Wollheim would agree). A life has to accumulate some characteristic markers of its reality that come from making contact with a time, place and cultural context. Categories and assumptions that structure what we do, and frame what counts as normal, acceptable, desirable, or needing to be explained, come largely from ongoing contact with an inherited world.

To expand on Wollheim's approach, we can use some ideas that Joseph Margolis builds into his conception of 'the human'. This excerpt comes from an even longer list of things Margolis claims to be constitutive of the human:

The human is artifactual; socially constituted; historicized; [..] real only within some culture's collective life; $[\ldots]$ indissolubly hybrid,

${ }^{18}$ Fernand Braudel on laying a table: "A table laid in the modern way and our present table manners are the results of many details that custom has imposed slowly, one by one, and in ways that vary according to region" (1992, p. 205). 
uniting biological and cultural processes and powers; [...] capable, thus, of functioning as a self, a person, a subject, an agent, within an aggregate of similarly formed selves [... ] (2009, p. 19).

On this account, meals and art can be viewed as contributing deeply to different aspects of human being. Meals are extremely effective ways of enacting multiple features of a culture's collective life, making a meaningful 'hybrid' out of the satisfaction of a biological need. If we are to have a life with more grip on reality than introspection can provide, a human context has to be realized in what we do in a collectively shareable and recognizable way. However, to incorporate the life of a person, as Wollheim terms it, we also need prompts for self-examination that allow us to assign meaning to our own experience. We need to ask what is interesting, good, important, and to be learned from in experience and need to develop terms we can use for comparison and choice. The demand that works of art place on us, to take care in building meaning from experience, speaks to this need in a searching way. Although to be people living human lives we have to surrender some of the meaning of our activities to what emerges within a collective life, we would not have meaningful lives if we did not also strive to make experience meaningful in conscious, individual relations to the world. Meals and art are not the only domains in which we can meet these needs, but they exemplify the contrasting modes well.

One question is whether one or the other of these modes of meaning-formation is more primary. Margolis perhaps suggests that it is the enculturation that is dominant; Wollheim perhaps prioritises the self-directed questioning. I have an under-explored tendency to agree with Wollheim. Would anyone care about a culture that was not anchored in people's experiences and pursuit of meaning? However, my goal is not to prioritise the art or the meal mode; each mode is important. And to return to my starting point, on this view, the prospect of eliminating meals - whether in the nutritional project of 'meal replacement' products or in a quest to identify meals as artshould be resisted. ${ }^{19}$

\footnotetext{
${ }^{19}$ Thanks to all the participants at the UNAM Food, Art, and Philosophy Conference for enjoyable and challenging discussion. I give special thanks to my respondent, David Fajardo, for his excellent comments, and to Sarah Bak-Geller, Patrik Engisch, Morgan Jones, Mohan Matthen, Gustavo Ortiz Millán, Uku Tooming, and Sarah Worth for further conversation. Great thanks to Paloma Atencia-Linares and Aaron Meskin for master-minding this project, for extensive, constructive comments on this paper, and for being such generous philosophers and hosts.
} 


\section{REFERENCES}

Abarca, Meredith, 2006, Voices in the Kitchen, Texas A\&M University Press, College Station.

Arnot, Chris, 1999, "Sculpting with Nukes", The Guardian (26/10/1999), downloaded from <https://www.theguardian.com/culture/1999/oct/26/ artsfeatures $>$

Bishop, Claire, 2004, "Antagonism and Relational Aesthetics", October 110, Fall, pp. 51-79.

Bourriaud, Nicolas, 2002, Relational Aesthetics, Les Presses du Réel, Dijon.

Braudel, Fernand, 1992, The Structures of Everyday Life, vol. 1, trans. Siân Reynolds, University of California Press, Berkeley.

Budd, Malcolm, 1995, Values of Art, Allen Lane The Penguin Press, London.

Chabad.Org, "What is a Seder?", downloaded from <https://www.chabad. org/holidays/passover/pesach_cdo/aid/1751/jewish/What-Is-a-Seder.htm $>$ [accessed: 30/1/20]

Douglas, Mary, 1982, In the Active Voice, Routledge and Kegan Paul, London.

Finkelstein, Joanne, 1989, Dining Out: A Sociology of Modern Manners, New York University Press, New York.

Giraldus, 1937, The Autobiography of Giraldus Cambrensis, trans. H.E. Butler, Cape Goliard Press, London.

Heydenreich, Ludwig, 1974, Leonardo: The Last Supper, Allen Lane The Penguin Press, London.

Irvin, Sherri, 2015, "Unreadable Poems and How They Mean", in John Gibson (ed.), The Philosophy of Poetry, Oxford University Press, Oxford, pp. 88-108.

John, Eileen, 2014, "Meals, Art, and Artistic Value", Estetika, vol. 51, no. 2 , pp. $254-268$.

Jones, Amelia, 2005, "The 'Sexual Politics' of The Dinner Party", in Norma Broude and Mary Garrard (eds.), Reclaiming Female Agency: Feminist Art History after Postmodernism, University of California Press, Berkeley, pp. 408-433.

Margolis, Joseph, 2009, The Arts and the Definition of the Human, Stanford University Press, Stanford.

Mothersill, Mary, 1991, Beauty Restored, Adams Bannister Cox Pubs, New York.

Nettel, Guadalupe, 2014, After the Winter, trans. Rosalind Harvey, Quercus, London.

Plakias, Alexandra, 2019, Thinking through Food, Broadview Press, Peterborough.

Robinson, Jenefer, 2005, Deeper than Reason, Clarendon Press, Oxford. Saito, Yuriko, 2007, Everyday Aesthetics, Oxford University Press, Oxford. 
Soylent UK website, <https://soylent-uk.com/> [accessed: 26/8/19]

Stecker, Robert, 2019, Intersections of Value, Oxford University Press, Oxford.

— , 2010, Aesthetics and the Philosophy of Art, 2nd ed. Lanham, Rowman and Littlefield Publishing, Maryland.

- 2003, Interpretation and Construction: Art, Speech, and the Law, Blackwell Publishing, Oxford.

Stokes, Rebecca, 2012, Inside/Out, MoMA/MoMA PS1 Blog (03/2/2012), downloaded from <https://www.moma.org/explore/inside_out/2012/02/ 03/rirkrit-tiravanija-cooking-up-an-art-experience/> [accessed: 14/9/19]

Strong, Roy, 2003, Feast: A History of Grand Eating, Pimlico, London.

Walton, Kendall, 1970, "Categories of Art", Philosophical Review, vol. 79, no. 3, pp. 334-367.

Widdicombe, Lizzie, 2014, "The End of Food", The New Yorker (12/5/14).

Withers, Josephine, 1992, "Judy Chicago's Dinner Party", in Norma Broude and Mary Garrard (eds.), The Expanding Discourse: Feminism and Art History, Westview Press, Boulder, pp. 451-465.

Wollheim, Richard, 1984, The Thread of Life, Cambridge University Press, Cambridge.

$\longrightarrow$, 1980, Art and Its Objects, Cambridge University Press, Cambridge.

Received: May 19, 2020; revised: November 9, 2020; accepted: November 20, 2020. 